\title{
The Relation between Human Capital and Economic Growth in MENA Countries
}

\author{
Hakan Acaroğlu \\ Eskisehir Osmangazi University, Department of Economics, Eskisehir, Turkey \\ Tel: +90 2222393750 - $1750 \quad$ E-mail: hacaroglu@ogu.edu.tr \\ Ayşen Altun Ada (Corresponding Author) \\ Dumlupinar University, Department of Banking and Finance, Kutahya, Turkey \\ Tel: +902742652031 - 4643 E-mail: aysaltun@ hotmail.com
}

Accepted: August 17, 2014

Doi:10.5296/ jpag.v4i3.6127 URL: http://dx.doi.org/10.5296/ jpag.v4i3.6127

\begin{abstract}
The aim of this study is to analyze the relation between human capital and economic growth for the years between 1990 and 2011 in 15 MENA (Middle East and North Africa) countries. Knowles and Owen's (1995) model which is based on Mankiw et al. (1992)'s Augmented Solow Model in principle is used as the economic model in the study. However, the statistical analysis is panel-data for the countries. Human capital is represented by both health and education at the same time. The findings show that public expenditure on human capital does not have any significant effect on economic growth neither in terms of health nor education. But this does not change the fact that when health and education quality are improved, the GDP per capita would increase, thus growth can be much more effective.
\end{abstract}

Keywords: Economic Growth, Human Capital, Panel Data 


\section{Introduction}

The impact of human capital on the economic growth has always been a matter of discussion in the field of economics. In this sense, the neo - classic growth model led by Solow (1956), new growth theory of Lucas (1988) and Romer (1990); the studies of Mankiw et al. (1992) who expanded the scope of the studies of Solow(1956) and the researches of Knowles and Owen (1995) for evaluating the impact of the health capital on the per capita income of the countries are the prominent studies. The neo - classic growth model of Solow (1956) focuses on the extraneous technology which identifies the input and output ratio and the population factor. According to this model, a balanced growth can only be ensured as long as the output and the physical capital are increased simultaneously and equally with the increase in the labor force. According to the model of Lucas (1988), the economic growth is sustained by the human capital stock. Due to the external reasons, both the physical capital and the human capital investments increase the long term economic growth rate. Romer (1990) argues that the growth depends on the human capital which is capable of bringing innovations and that the innovations encourage the technologic advancements and the economic growth. Mankiw et al. (1992) expand the scope of the Solow model by covering the physical capacity and human capital as well. In this sense, they addressed the internal growth approaches while maintaining the theories about the technologic advancements which are under the impact of the external factors and about all returns on capital. With the studies of Mankiw et al. the human capital has started to be included in the empirical growth models, and these studies were followed by the studies of Knowles and Owen (1995). Knowles and Owen (1995) used the core data set of Mankiw et al. (1992) in their study. They aimed to examine the possible impact of taking a representative variable for health capital in the empirical growth model. They found a strong and robust correlation between life expectancy and income per capita. They have concluded that the relation between health capital and income per capita is stronger than the relation between educational capital and income per capita.

The issue of whether the human capital has an impact on the economic growth or not is very complicated. Because, the relation between human capital and economic growth has been well discussed in the related literature in different times and on different countries. In this study, the relation between the human capital and the economic growth has been elaborated in the light of the situations in 15 MENA $^{1}$ countries. The data collected between 1990 and 2011 are analyzed according to the method of panel data analysis. Altun Ada and Acaroğlu (2014) data set is used. ${ }^{2}$

In this paper, where the model developed by Knowles and Owen was used, the relation between human capital and economic growth is analysed, the concepts of education and health are handled together as human capital variables.

\footnotetext{
${ }^{1}$ According to the definition of the World Bank, there are 21 MENA countries, however, only 15 of them are observed in this study due to the limited access to the related data.

${ }^{2}$ Education and health variables are addressed separately and we relied on The Augmented Solow Model as it is used in Mankiw et. al. (1992) within the Altun Ada and Acaroğlu (2014). But in this study, the education and health variables are observed jointly following the Knowles and Owen (1995) model.
} 


\section{Literature Review}

In the literature, there are several empirical studies which separately focus on the effect of variables related to health and education on economic growth as well as the studies that focus on both of them. In many of these studies, while two human capital variables are handled separately, some of the studies handled them together to compare their effects on economic development. We have reviewed the papers addressing jointly the issues of education and health.

Mankiw et al. (1992) studied on the effect of health and education expenditures on economic growth; and they expanded Solow (1956) model with human capital and showed that regarding growth, human capital is as important as physical capital. According to this research, which included 98 countries between for 1960-1985 periods, human capital has a direct and significant contribution on growth. In Landau's (1997) study, which analyzed the impact of state spending for human capital in the fields of education and healthcare, on economic growth and real human capital; it was concluded that differences in state spending for human capital have no statistical impact on the economic growth and have limited impact on the real levels of education and healthcare. Webber (2002) analyzed the relations between health and education the two components of human capital, and economic growth. His study was for the 46 countries and the period of 1960-1990. He argued that it is necessary for growth oriented policies to concentrate on investments for education, not for health. Huang et al. (2008) conducted a study on 22 OECD countries and Taiwan; in this analysis they researched the impacts of human capital in the field of healthcare, human capital in the field of education and increases in physical capital on economic growth; and analyzed external influence of human capital according to the low income and high income countries. The findings of this study show that human capital especially in the field of healthcare, contributes to the economic growth. Human capital in the field of education is second and external influence of human capital is third big factors. Due to the external influence, the group of high income countries relatively increases human capital -in the field of educationand physical capital. However, in the group of low income countries, the contribution of human capital in the field of healthcare reflects directly to the human capital and does not have any external influence. Baldacci et al. (2008) conducted a study with the purpose of determining the relation between social expenditures, human capital and growth by using panel data of 118 developing countries. In this study, in which they drew on data covering 1971-2000, they compared the impacts of alternative economic interventions. They concluded that education and health expenditures directly and positively impact the accumulation of health and educational capital, and that these expenditures indirectly and positively affect growth. Li and Huang (2009) employed panel data analysis in their study in which they addressed the relation between real GDP rise in the production function and physical capital, human capital and health investments. In the study in which they drew on provincial data for 1978-2005 from China, they examined the extended model of Mankiw et al. (1992). They found that health and education have a positive effect on economic growth, and that the interaction between health and educational accumulation does not halt growth. They advise the Chinese policy makers to increase economic growth by improving the 
growth level in the fields of health or education, and they argue that investments in education are more important than investments in health. Colantonio et al. (2010) examined the relation between growth level indicators in the fields of education, health and economy pertaining to several Sub-Saharan African countries. Based on these indicators, the countries were classified for the period of 2003-2007 in terms of proximity and distance. They found, using the multidimensional scaling method, that there exists a high-level correlation among educational, health and economic growth level indicators. Azam and Ahmed (2010), in their study aimed at investigating the impacts of education and health upon Pakistan's economic growth level, employed multiple linear regression model and least squares method. They covered the period of 1960-2009, and found that the impact of health and education upon economic growth is positive and statistically significant. The authors advised policy makers in Pakistan to improve the quality of education and healthcare services to support economic growth. Li and Huang (2010) conducted a research among a group of East Asian countries, including China; and assessed the resources of economic growth by using empirical analyses. They approached to the human capital from health and education aspects. Also, they paid attention to the period between 1961 and 2007; and sub-sampling of Asian financial crisis that happened after the year 1997 was calculated in order to make a comparison. According to the statistical results, the impact of the education investments on economic growth is fragile; on the other hand, the impact of healthcare investments on economic growth is relatively stronger. Haldar and Mallik (2010) examined the time-series behavior of the investments made in physical capital and human capital in India between 1960 and 2006 within the framework of cointegration. They found that while investments in physical capital is not effective neither in the short-run nor in the long-run, investments in human capital that consists of education and health components have a long-term significant impact upon GNP per capita. Another important finding of their study is that the change in investments in educational capital positively affects the changes in investments in educational capital, investments in health capital and GNP growth. Jajri and Ismail (2012) analyzed the relation between human capital and economic growth in Malaysia for the 1980-2009 period. Augmented aggregate production function was used as the growth model. While public expenditure on education was dealt with as human capital variables for health, life expectancy and education, economic growth was calculated based on real gross domestic product. According to the findings of the study, while traditional inputs such as capital and work force have statistical significance both in the short and long run, human capital variables do not have an effect on growth in the long run. It was concluded that human capital variables have a significant influence on growth in the short run. The authors found out that the education system in Malaysia needs to generate a more efficient work force to reinforce the effect of human capital on economic growth. Amin et al. (2012) analyzed the effect of investment in human capital on the economy of Pakistan. The 2000-2010 period was investigated in their study and education and health variables represented human capital. In the study in which Cobb - Douglas production function was utilized, proxy variables like elementary, middle and high school enrollment rates, the number of people per bed, the number of people per doctor, infant mortality rates and life expectancy were used. The empirical results obtained were complicated. When human capital investment was considered 
as the production factor, direct proportion was found between all proxy variables and growth. While inverse proportion was observed between the number of people per doctor and middle school enrollment rates out of proxy variables and growth, it was found that when these proxy variables are studied with employed work force to calculate active work force, only the high school enrollment rates were inversely proportional with the economic growth. Javed et al. (2013) applied co-integration and error correction techniques to time series data of the 1978-2008 period in their study in which they analyzed the effects of investments in education and health sectors on the growth performance of Pakistan. According to the findings of their research, while investment in the health sector has short term positive and statistical effect on economic growth, investment in the education sector has long term positive effects. According to the authors, investment in health and education sectors has highly significant positive effects on gross domestic product of Pakistan. They claim that Pakistan has a high potential to reach a higher growth level through investments in human capital in education and health sectors and they state that this potential is not utilized by the country. Therefore, they recommend that both the quality and quantity of health and education services should be enhanced.

\section{Theory}

If we add Mankiw, Romer and Weil (1992) (MRW) augmented Solow's (1956) model to health capital which is also a component of human capital, we get an extended Cobb-Douglas production function form as Knowles and Owen (1995) used.

$Y_{i t}=K_{i t}^{\alpha} E_{i t}^{\beta} X_{i t}^{\psi}\left(A_{i t} L_{i t}\right)^{1-\alpha-\beta-\psi}$

In Eq (1), $\mathrm{Y}$ is real output. $\mathrm{K}$ is the stock of physical capital. $\mathrm{E}$ is the stock of educational human capital. $\mathrm{X}$ is the stock of health capital. $\mathrm{L}$ is the labour input and $\mathrm{A}$ is the level of technology of a country. While the subscript refers to country $i, t$ subscript refers to time period. Thus, Eq (1) can be expressed as in below;

$y_{i t}=k_{i t}^{\alpha} e_{i t}^{\beta} x_{i t}^{\psi}$

Eq (2) helps representing the quantities in per effective unit of labour. MRW assumes the labour and technology level for countries in a definite period in below.

$L_{i t}=L_{i 0 \exp }\left(n_{i} t\right)$

$A_{i t}=A_{t}=A_{0} \exp (g t)$

In Eq (3) and Eq (4), $n_{i}$ and $g$ are the exogenous rates of growth of the labour force in country $\mathrm{i}$ and technology. So the accumulation of physical, educational and health capital can be expressed as; 


$$
\begin{aligned}
& \dot{k}_{i t}=s_{k i} y_{i t}-\left(n_{i t}+g_{t}+\delta_{t}\right) k_{i t} \\
& \dot{e}_{i t}=s_{e i} y_{i t}-\left(n_{i t}+g_{t}+\delta_{t}\right) e_{i t} \\
& \dot{x}_{i t}=s_{x i} y_{i t}-\left(n_{i t}+g_{t}+\delta_{t}\right) x_{i t}
\end{aligned}
$$

In Eq (5), Eq (6) and Eq (7); $s_{\mathrm{ki}}, \mathrm{s}_{\mathrm{ei}}$ and $\mathrm{s}_{\mathrm{xi}}$ are the portions of income in country i invested in physical, educational and health capital, respectively. $\delta$ is a common depreciation rate.

By following MRW and Knowles and Owen, if the assumption of steady state (with $\alpha+\beta+\psi$ $<1$ ), the Eq (5), Eq (6) and Eq (7) take the form below;

$$
\begin{aligned}
& k_{i}^{*}=\left(\frac{s_{k i}^{1-\beta-\psi} s_{e i}^{\beta} s_{x i}^{\psi}}{n_{i}+g+\delta}\right)^{1 / \eta} \\
& e_{i}^{*}=\left(\frac{s_{k i}^{\alpha} s_{e i}^{1-\alpha-\psi} s_{x i}^{\psi}}{n_{i}+g+\delta}\right)^{1 / \eta} \\
& x_{i}^{*}=\left(\frac{s_{k i}^{\alpha} s_{e i}^{\beta} s_{x i}^{1-\alpha-\beta}}{n_{i}+g+\delta}\right)^{1 / \eta}
\end{aligned}
$$

In Eq (8), Eq (9) and $\mathrm{Eq}(10){ }^{*}$ represents the steady states values and $\mathrm{n} \equiv 1-\alpha-\beta-\psi$. By substituting $\mathrm{Eq}(8)$ in $\mathrm{Eq}(10)$ and $\mathrm{Eq}$ (4) in Eq (2) and taking natural logs, the extended version of MRW's Eq is obtained below;

$$
\ln \left(\frac{Y_{i t}}{L_{i t}}\right)=\ln A_{0}+g t-\frac{1-\eta}{\eta} \ln \left(n_{i}+g+\delta\right)_{t}+\frac{\alpha}{\eta} \ln \left(s_{k i}\right)+\frac{\beta}{\eta} \ln \left(s_{e i}\right)+\frac{\psi}{\eta} \ln \left(s_{x i}\right)
$$

In addition to this, by solving Eq (9) and Eq (10) for $s_{e i}$ and $s_{x i}$ in terms of $e_{i}{ }^{*}$ and $x_{i}{ }^{*}$ and substituting in Eq (11) the Eq (12) is obtained below;

$$
\ln \left(\frac{Y_{i t}}{L_{i t}}\right)=\ln A_{0}+g t+\frac{\alpha}{1-\alpha}\left(\ln \left(s_{k i}\right)-\ln \left(n_{i}+g+\delta\right)_{t}\right)+\frac{\beta}{1-\alpha} \ln \left(e_{i}^{*}\right)+\frac{\psi}{1-\alpha} \ln \left(x_{i}^{*}\right)
$$

And by solving Eq (10) for $\mathrm{s}_{\mathrm{xi}}$ and substituting in $\mathrm{Eq}$ (11) the $\mathrm{Eq}$ (13) is obtained below;

$$
\ln \left(\frac{Y_{i t}}{L_{i t}}\right)=\ln A_{0}+g t-\frac{\alpha+\beta}{1-\alpha-\beta} \ln \left(n_{i}+g+\delta\right)_{t}+\frac{\alpha}{1-\alpha-\beta} \ln \left(s_{k i}\right)+\frac{\beta}{1-\alpha-\beta} \ln \left(s_{e i}\right)+\frac{\psi}{1-\alpha-\beta} \ln \left(x_{i}^{*}\right)
$$


In the following parts the data is identified and the panel data regressions are run depending on the the Eq (12) by using the steady state values of education and health variables. If someone wants she may execute the Eq (13) with the border of her data availability.

\section{Data}

The annual data used in this study is for the years between 1990 and 2011. The data set is taken from Altun Ada and Acaroğlu (2014) and is available for 15 MENA countries. They are Algeria, Bahrain, Djibouti, Egypt Arab Republic, Iran, Jordan, Malta, Morocco, Oman, Syrian Arab Republic, Tunisia, United Arab Emirates, Kuwait, Lebanon and Israel. It is stated by the World Bank that there are 21 MENA countries. There is no other reason than the availability of access to information for choosing 15 of them. Data compiled from the statistics of World Bank, IMF, OECD, UNESCO as in their official websites is used in this study. Besides, for some years, statistics from the official websites of some states have been used as a data source.

We use three different proxies for the rate of human capital accumulation $\left(\mathrm{s}_{\mathrm{h}}\right)$. The proxies for health are life expectancy at birth, fertility rate total (births for woman), health expenditure public ( $\%$ of GDP). The proxies for education are primary completion rate total (\% of relevant age group), pupil teacher ratio primary and public spending on education total (\% of GDP). The dependent variable in the model is derived from Gross Domestic Product (GDP) per capita Purchasing Power Parity (PPP). Data are in constant 2005 international dollars. The dependent variable is obtained from multiplying GDP per capita and labour force/population. And after multiplication the log is taken. Within the scope of this work, the letter " $n$ " stood for the average growth rate of the working age population which cover the people over 15 years old meeting the necessary ILO criteria to be regarded as an economically active population. The letter "s" stood for the average rate of real GDP investment while the letters $\mathrm{Y}$ and L defined the GDP rates according to the working age group in 2005. By using Stata 10, we have created fixed and random effects and executed the arranged the panel data according to stated MENA countries and years.

\section{Results and Discussion}

The Eq (12) in theory is tested for the relation between human capital and economic growth in this study. To get our dependent variable coded as X15; the natural log of GDP per working people in 1990-2011, we multiply GDP per capita, PPP with labor force / population and then we take the natural logarithm of this multiplication. This approach is taken from Knowles and Owen (1995) in which their dependent variable log difference GDP per working age person. Table 1 presents estimation of the Augmented Solow Model with Panel Data with Fixed and Random Effects. The independent variables that we use are $s_{k i},(n+g+\delta)_{t}, e_{i}$ and $x_{i}$. While, $s_{k i}$ is the fraction of income, $(n+g)$ is the growth rate of effective units of labor, $\mathrm{A}(\mathrm{t}) \mathrm{L}(\mathrm{t})$, and $\delta$ is the rate of depreciation respectively, $\mathrm{e}_{\mathrm{i}}$ is the educational capital and $\mathrm{x}_{\mathrm{i}}$ is the health capital. We take the natural log of all variables.

The three proxies for health capital variables that we use are; life expectancy at birth total years (X3), fertility rate total (births per woman) (X4), public health expenditure (\% of GDP) 
(X5) respectively. The other three proxies for educational capital variables that we use are; primary completion rate total (\% of relevant age group) (X6), pupil teacher ratio primary (X7), total public spending on education (\% of GDP) (X8), respectively. In Table 1 X19, X20, X21 are the natural log of health capital proxies. And X22, X23, X24 are the natural log of educational capital proxies.

We consider all possible combinations of health and education variables using Fixed and Random Effect estimation with panel data. As a result, we have three different health and education proxies; we will have nine possible combination results. These results are shown in Table 1 below, from second column to tenth column. The standard error values are stated in parenthesis.

Table 1. Estimation of the Augmented Solow Model with Panel Data

\begin{tabular}{|c|c|c|c|c|c|c|c|c|c|}
\hline \multicolumn{3}{|l|}{ Fixed Effect Regression } & \multicolumn{7}{|c|}{$\begin{array}{l}\text { HealthVariables:X3,X4,X5(X19,X20,X21) } \\
\text { Education Variables:X6, X7, X8 (X22, X23, X24) }\end{array}$} \\
\hline Sample: & $\mathrm{X} 22-\mathrm{X} 19$ & $\mathrm{X} 22-\mathrm{X} 20$ & $\mathrm{X} 22-\mathrm{X} 21$ & $\mathrm{X} 23-\mathrm{X} 19$ & $\mathrm{X} 23-\mathrm{X} 20$ & $\mathrm{X} 23-\mathrm{X} 21$ & $\mathrm{X} 24-\mathrm{X} 19$ & $\mathrm{X} 24-\mathrm{X} 20$ & $\mathrm{X} 24-\mathrm{X} 21$ \\
\hline \multirow[t]{2}{*}{ Observations/ Groups } & $327 / 15$ & & & & & & & & \\
\hline & $-7.21^{*}$ & $6.93^{*}$ & $4.63^{*}$ & -1.75 & $9.76^{*}$ & $10.10^{*}$ & $-7.37^{*}$ & $8.73^{*}$ & $7.83^{*}$ \\
\hline \multirow[t]{2}{*}{ Constant } & (1.12) & $(0.35)$ & $(0.37)$ & $(1.22)$ & $(0.16)$ & $(0.19)$ & (1.23) & $(0.08)$ & $(0.10)$ \\
\hline & -0.01 & $0.02^{* * *}$ & 0.02 & -0.01 & 0.02 & 0.02 & -0.01 & $0.04^{* *}$ & $0.06^{*}$ \\
\hline \multirow[t]{2}{*}{$\ln \left(\mathrm{s}_{\mathrm{ki}}\right)-\ln \left(\mathrm{n}_{\mathrm{i}}+\mathrm{g}+\delta\right)_{\mathrm{t}}$} & $(0.02)$ & $(0.02)$ & $(0.02)$ & $(0.02)$ & $(0.02)$ & $(0.02)$ & $(0.02)$ & $(0.02)$ & $(0.02)$ \\
\hline & $0.54^{*}$ & $0.40^{*}$ & $0.78^{*}$ & $-0.52^{*}$ & $-0.38^{*}$ & $-0.72^{*}$ & -0.02 & 0.04 & 0.05 \\
\hline \multirow[t]{2}{*}{$\ln \left(\mathrm{e}_{\mathrm{i}}^{*}\right)$} & $(0.07)$ & $(0.07)$ & $(0.09)$ & $(0.06)$ & $(0.06)$ & $(0.06)$ & $(0.05)$ & $(0.04)$ & $(0.06)$ \\
\hline & $3.03^{*}$ & $-0.58^{*}$ & -0.02 & $2.68^{*}$ & $-0.51^{*}$ & $0.14^{*}$ & $3.63^{*}$ & $-0.68^{*}$ & $0.13^{* *}$ \\
\hline $\ln \left(\mathrm{x}_{\mathrm{i}}^{*}\right)$ & $(0.28)$ & $(0.05)$ & $(0.06)$ & $(0.27)$ & $(0.05)$ & $(0.05)$ & $(0.29)$ & $(0.04)$ & $(0.07)$ \\
\hline R-sq within & 0.44 & 0.50 & 0.23 & 0.50 & 0.51 & 0.35 & 0.35 & 0.45 & 0.03 \\
\hline R-sq between & 0.32 & 0.30 & 0.22 & 0.51 & 0.50 & 0.56 & 0.37 & 0.16 & 0.03 \\
\hline R-sq overall & 0.32 & 0.27 & 0.20 & 0.48 & 0.41 & 0.48 & 0.35 & 0.15 & 0.01 \\
\hline F-statistics & $81.97^{*}$ & $101.91^{*}$ & $30.17^{*}$ & $101.28^{*}$ & $107.44^{*}$ & $55.21^{*}$ & $55.14^{*}$ & $84.71^{*}$ & $3.55^{* *}$ \\
\hline
\end{tabular}

Health Variables:X3, X4, X5 (X19, X20, X21)

Random Effect Regression

Education Variables:X6, X7, X8(X22, X23, X24)

\begin{tabular}{llllllllll}
\hline Sample: & $\mathrm{X} 22-\mathrm{X} 19$ & $\mathrm{X} 22-\mathrm{X} 20$ & $\mathrm{X} 22-\mathrm{X} 21$ & $\mathrm{X} 23-\mathrm{X} 19$ & $\mathrm{X} 23-\mathrm{X} 20$ & $\mathrm{X} 23-\mathrm{X} 21$ & $\mathrm{X} 24-\mathrm{X} 19$ & $\mathrm{X} 24-\mathrm{X} 20$ & $\mathrm{X} 24-\mathrm{X} 21$ \\
\hline Observations/Groups & $327 / 15$ & & & & & & & & \\
& $-7.30^{*}$ & $6.92^{*}$ & $4.61^{*}$ & -1.82 & $9.82^{*}$ & $10.17^{*}$ & $-7.58^{*}$ & $8.75^{*}$ & $7.86^{*}$ \\
Constant & $(1.16)$ & $(0.45)$ & $(0.48)$ & $(1.25)$ & $(0.27)$ & $(0.28)$ & $(1.26)$ & $(0.29)$ & $(0.28)$ \\
$\ln \left(\mathrm{s}_{\mathrm{ki}}\right)-\ln \left(\mathrm{n}_{\mathrm{i}}+\mathrm{g}+\delta\right)_{\mathrm{t}}$ & -0.01 & 0.02 & 0.02 & -0.01 & 0.02 & 0.02 & -0.01 & $0.04^{* *}$ & $0.06^{*}$
\end{tabular}




\begin{tabular}{llllllllll} 
& $(0.02)$ & $(0.02)$ & $(0.02)$ & $(0.02)$ & $(0.02)$ & $(0.02)$ & $(0.02)$ & $(0.02)$ & $(0.02)$ \\
$\ln \left(\mathrm{e}_{\mathrm{i}}^{*}\right)$ & $0.54^{*}$ & $0.41^{*}$ & $0.79^{*}$ & $-0.54^{*}$ & $-0.39^{*}$ & $-0.74^{*}$ & -0.03 & 0.03 & 0.04 \\
& $(0.07)$ & $(0.07)$ & $(0.09)$ & $(0.06)$ & $(0.06)$ & $(0.06)$ & $(0.05)$ & $(0.04)$ & $(0.06)$ \\
$\ln \left(\mathrm{x}_{\mathrm{i}}^{*}\right)$ & $3.05^{*}$ & $-0.58^{*}$ & -0.02 & $2.71^{*}$ & $-0.51^{*}$ & $0.14^{*}$ & $3.69^{*}$ & $-0.68^{*}$ & $0.14^{* *}$ \\
R-sq within & $(0.28)$ & $(0.05)$ & $(0.06)$ & $(0.27)$ & $(0.05)$ & $(0.06)$ & $(0.29)$ & $(0.04)$ & $(0.07)$ \\
R-sq between & 0.44 & 0.50 & 0.23 & 0.50 & 0.51 & 0.35 & 0.35 & 0.45 & 0.03 \\
R-sq overall & 0.32 & 0.30 & 0.22 & 0.51 & 0.51 & 0.57 & 0.37 & 0.17 & 0.01 \\
Wald & 0.32 & 0.27 & 0.20 & 0.48 & 0.41 & 0.48 & 0.35 & 0.15 & 0.01 \\
\hline
\end{tabular}

Note: $* * *$ and $* * *$ indicates $1 \%, 5 \%$ and $10 \%$ significance level.

The overall R-squares for Fixed Effect regressions are changing between 0.01 and 0.48 , as it is seen in Table 1 from the ninth row. While the educational capital variable is statistically significant except for "X24-X19, X24-X20 and X24-X21" proxies as is shown in fifth row, the health capital variable is statistically significant except for "X22-X21" proxy. On the other hand, the overall R-squares for Random Effect regressions are changing between 0.01 and 0.48 from Table 1 before the last row. The statistical significances protect their values same as discussed in Fixed Effect results.

The comparison of Fixed and Random Effects give the same results both the significance level of variables and their signs. The only difference causes from the magnitudes. According to individually evaluated results; when the educational capital is concerned, primary completion rate is positively correlated with dependent variable including all health capital proxies. However, pupil teacher ratio is negatively correlated with dependent variable including all health capital proxies. But there aren't any correlation between public spending on education and dependent variable including all health capital proxies. On the other hand, when the health capital is considered, primary completion rate is positively correlated with dependent variable including life expectancy in birth but it is negatively correlated with the dependent variable including fertility rate. In addition, pupil teacher ratio is positively correlated with dependent variable for included life expectancy at birth and public health expenditure, and negatively correlated for included fertility rate. At last, public spending on education is positively correlated with dependent variable including life expectancy in birth and public health expenditure, and negatively correlated including fertility rate.

The interesting finding in this study is, when the educational capital is concerned the insignificant relation between dependent variable and public spending on education with all included health variables show that growth in Mena countries do not depend on public spending on education. We see the replication of this argument in both Fixed and Random Effect regressions. In addition to this, when the health capital is considered the insignificant relation between dependent variable and primary completion rate with included public health expenditure show that growth in Mena countries also is not affected by public spending on 
health.

\section{Concluding Remarks}

The aim of this study is to analyze the relation between human capital and economic growth for the years between 1990 and 2011 in 15 MENA countries. The panel-data estimation is used as the statistical method in this study. Fixed and Random-effect results are obtained and displayed for comparison.

To predict the economic model used in this paper, taken from Knowles and Owen (1995) that is basically depends on Mankiw et al. (1992)'s Augmented Solow Model, three different proxies for both health and education are used. In this paper, education and health variables have jointly been analyzed. While the proxies for health are life expectancy at birth, fertility rate and public health expenditure, the proxies for education are primary education are primary education completion rate, pupil teacher ratio and public education expenditure. The prediction of GDP per capita can be improved if the data on human capital is available.

An analysis of the health variable component for human capital reveals that the statistically insignificant proxies in regression is the combination of public health expenditure and primary completion rate. This finding shows that if the quality of health is improved the GDP per capita would increase, thus growth can be much more effective. However, something about public heath expenditure goes wrong as far as the GDP per capita growth is concerned. The other combinations are all significant for health variable. Analysis of education variable suggests that the significant proxies are all the combinations of selected proxies except for the combination of public spending on education with all other health proxies. Within the scope of the Proxy combination we have reached, this finding shows that if the quality of education is improved the GDP per capita would increase, thus growth can be much more effective. However, something about public education expenditure goes wrong as far as the GDP per capita growth is concerned. It should be noted that, both in terms of health and education the public spending for human capital has no significance on GDP per capita in MENA countries.

The concept of human capital has been more prevalent in the development and growth agenda of the MENA countries recently. As a result of the fact that the policy makers are of the opinion that the human capital contributes a lot to the economic development and growth, the investments in the education and health sector have increased as well. In this sense, many of the countries in the region have undertaken to improve education and health services. One of the leading reasons for this study to focus on the MENA countries is that the quality of education and health services in these countries are far below the world standards despite huge investments and this situation poses a great obstacle against development of MENA countries. It is possible to explain the reasons of the results by failures in using the resources in MENA countries and the fact that these countries are under developed. It is also possible that the results are affected by political views in the case that the decision makers of the MENA countries elaborately evaluate these findings. 


\section{References}

Altun Ada, A. Acaroğlu, H. (2014). Human Capital and Economic Growth: A Panel Data Analysis with Health and Education for MENA Region. Advances in Management \& Applied Economics. 4(4). 59-71.

Amin, A. Zilakat, K. Ma. Farzana, S.(2012). Human Capital Investment: Its Impact on the Economic Growth of the Country (A Case of Pakistan: 2000 to 2010). PUTAJ Humanities and Social Sciences. 19. 151-160.

Azam, M. Ahmed, A. (2010). The Role of Human Capital in Economic Development: Evidence from Pakistan: 1961-2009. Interdisciplinary Journal of Contemporary Research in Business.2(4). 220-233.

Baldacci, E. Clements, B. Gupta, S.Cui, Q. (2008). Social Spending, Human Capital, and Growth in Developing Countries. World Development. 36(8). 1317-1341.

Colantonio, E. Marianacci, R. Mattoscio, N. (2010). On Human Capital and Economic Development: Some Results For Africa. Procedia-Social and Behavioral Sciences. 9. 266-272.

Haldar, S. K. Mallik, G. (2010). Does Human Capital Cause Economic Growth? A case Study of India. International Journal of Economic Sciences and Applied Research. 3(1). 7-25.

Huang, M.L. Hwang J.T. Chen M.R.(2008). Health, Human Capital and Economic Growth: An International Comparison Study. The Journal of American Academy of Business. 14(1). 110-122.

Jajri, I. Ismail, R.(2012). An Analysis of Relationship Between Human Capital and Economic Growth. Life Science Journal. 9(4). 3735-3742.

Javed, M. Abbas S. Fatima A.(2013). Impact of Human Capital Development on Economic Growth of Pakistan: A Public Expenditure Approach. World Applied Sciences Journal 24(3). 408-413.

Knowles, S. Owen, P.D. (1995). Health Capital and Cross-Country Variation in income per capita in the Mankiw-Romer-Weil Model. Economics Letters. 48. 99-106.

Landau, D. L. (1997). Government Expenditure, Human Capital Creation and Economic Growth. Journal of Public Budgeting, Accounting \& Financial Management. 9(3). 467-487.

Li, H. Huang, L. (2009). Health, Education, and Economic Growth in China: Empirical Findings and Implications. China Economic Review. 20(3). 374-387.

Li, H. Huang, L.(2010). Health, Education, and Economic Growth in East Asia. Journal of Chinese Economic and Foreign Trade Studies. 3(2).110-131.

Lucas, R.E Jr. (1988). Money Demand in the United States: A Quantitative Review. Carnegie-Rochester Conference Series on Public Policy. 29. 137-168 


\section{Macrothink}

Journal of Public Administration and Governance ISSN 2161-7104 2014, Vol. 4, No. 3

Mankiw, N. G. Romer, D. Weil, D. N. (1992). A Contribution to the Empirics of Economic Growth. Quarterly Journal of Economics. 107(2). 407-437.

Romer P. (1990). Human Capital and Growth: Theory and Evidences. Carnegie-Rochester Conference Series on Public Policy 32(1). 251-286.

Solow, R. (1956). A Contribution to the Theory of Economic Growth. Quarterly Journal of Economics. 70/1. 65-94.

Webber, D.J. (2002). Policies to Stimulate Growth: Should We Invest in Health or Education. Applied Economics. 34(13).1633-1643. 